\title{
Formulation and Evaluation of Sunscreen Gels Containing Mangiferin Isolated from Phaleria macrocarpa Fruits
}

\author{
Aprilita Rina Yanti Eff ${ }^{1, *}$, Sri Teguh Rahayu ${ }^{1}$, Henny Saraswati ${ }^{1}$, Abdul Mun'im ${ }^{2}$ \\ 'Department of Pharmacy, Faculty of Health Sciences Universitas Esa Unggul, West Jakarta, INDONESIA. \\ 2Department of Pharmacognosy-Phytochemistry, Faculty of Pharmacy, Universitas Indonesia, Kampus UI Depok, West Java, INDONESIA.
}

\begin{abstract}
Objectives: Ultraviolet (UV)-mediated photoreaction and photo-oxidation damage the skin, which can be prevented by using sunscreens as photo protective agents. Mangiferin is a major constituent of Phaleria macrocarpa fruits that has both sunscreen and antioxidant activity. This study aimed to formulate and evaluate sunscreen gel made from mangiferin isolated from P. marcocarpha fruits. Methods: Sunscreen gels were formulated using three different concentrations of mangiferin $(1.25 \%, 2.5 \%$, and $5 \%)$ and their physicochemical parameters (color, odor, homogeneity, spread ability, $\mathrm{pH}$, and accelerated stability) were tested. The in vitro Sun Protection Factor (SPF) of the gels was determined using UV spectrophotometry. Sensory evaluation (hedonic test) was performed with a panel of 32 untrained panelists. Skin irritation test was conducted on 20 female volunteers using a skin patch. Results: The three mangiferin sunscreen gels showed high absorbance at wavelengths of $290-360 \mathrm{~nm}$. The SPF was 11.2, 38.6, and and 88.53 at a mangiferin concentration of $1.25 \%, 2.5 \%$, and $5 \%$, respectively. The gels' pH was in the proper range (5.8-6.0), and they showed good spread ability, no phase separation, and acceptable consistency. They were
\end{abstract}

found to be stable during a two-month stability study. A gel containing $2.5 \%$ concentration of mangiferin is the most preferred formula. In addition, they did not irritate the skin. Conclusion: Gels formulation containing mangiferin at concentrations of $1.25,2.5$, and $5 \%$ are effective as sunscreens. The gel meets the requirements on physicochemical parameters and is stable for two months storages at temperatures $8^{\circ} \mathrm{C}, 25^{\circ} \mathrm{C}$ and $40^{\circ} \mathrm{C}$.

Key words: Gel, Sunscreen, Mangiferin, Phalleria marcocarpha, SPF.

Correspondence

Dr. Aprilita Rina Yanti Eff,

Department of Pharmacy, Faculty of Health Sciences Universitas Esa Unggul, West Jakarta-11510, INDONESIA.

Phone no: +628129939727

Email: aprilita.rinayanti@esaunggul.ac.id

DOI: 10.5330/ijpi.2019.3.26

\section{INTRODUCTION}

A sunscreen is a photoprotective agent against direct Ultraviolet (UV) radiation and is used as the skin's defense against the harmful effects of direct UV radiation. Broad-spectrum sunscreens that progressively reduce the harmful effects of direct UV radiation are now being developed. ${ }^{1}$ Synthetic photoprotective agents can be potentially toxic and carcinogenic and therefore phytoconstituents are becoming popular as essential ingredients of cosmetic formulations because they are natural; have antimutagenic, anticarcinogenic and nontoxic effects; and can severely inhibit the complex process of carcinogenesis. Cosmetics containing natural herbal components are less irritating to the skin, especially skin that is hypoallergic, ${ }^{2}$ contains native ingredients and can rejuvenate and adequately protect the skin from environmental pollution, atmospheric temperature fluctuations, UVA and UVB radiation, hyperpigmentation and aging. The use of bioactive compounds in cosmetic formulations has increased in recent years because of their safety, lack of side effects, absence of dangerous synthetic compounds that cause health hazards and ecological sustainability. ${ }^{1,3}$ Additionally, bioactive compounds have many pharmacological properties; for example, they are natural antioxidants, natural preservatives, hypoallergenic compared to synthetic products and environmentally friendly. ${ }^{4}$

Phaleria macrocarpa (Mahkota dewa) is a medicinal plant found in Papua, Indonesia. It has long been used as a cure for various diseases such as cancer, liver disease, heart disease, diabetes, arthritis, kidney disease, stroke and hypertension. Besides containing alkaloids, saponins, polyphenols, phenolics glycosides, dodecanoic acid, palmitic acid, ethyl stearate and sucrose, ${ }^{5,6}$ P. macrocarpa fruits also contain benzophenone and naturally derived active compounds that possess effective sunscreen activity. Creams and lotions containing the ethanol extract of $P$. macrocarpa show sunscreen activity in vitro. ${ }^{7}$ The benzophenone and xanthone glucosides present in $P$. macrocarpa fruits are mahkoside A, mangiferin and 6,4-dihydroxy-4-methoxybenzophenone-2-O- $\beta$-gentiobioside $(6,4$ DHMP). Natural products, such as mangiferin, offer an innovative solution for modern consumers of cosmetic formulations because they have antiphotoaging, antioxidant and anti-inflammatory activities. Our previous study has shown that mahkoside A, mangiferin and 6,4-DHMP have sunscreen activity in vitro and in vivo. Mangiferin at a concentration of $500 \mu \mathrm{g} / \mathrm{mL}$ has a sun protection factor (SPF) of 15.83 and is typically categorized as a sunscreen. Studies have also shown that the application of mangiferin $25 \%$ did not cause irritation and allergic reaction with the erythema severity and erythema diameter are both zero. ${ }^{8}$ Topical application of mangiferin inhibits the increase of skin thickness, wrinkle formation and acute edema in UVB-irradiated mice. ${ }^{9}$ Mangiferin also shows significant protection against DNA damage and can increase the photoprotective effect of sunscreens. ${ }^{10}$

Gels are forms of topical dosage that can be properly applied and have excellent stability compared to creams and ointments. Gels also provide controlled release compared to other semisolid formulations. ${ }^{11}$ Stability testing is a common procedure performed on a cosmetic or drug product. Accelerated stability testing is an initial step that is carried out by using various storage temperatures and humidity to evaluate the possibility of product degradation after long-term storage. ${ }^{5}$ Stability tests of medicinal and cosmetic formulations ensure their strength, quality and purity. 
A gel formulation is considered stable if its properties and characteristics stay within acceptable limits for a specific period of normal temperature not exceeding $25^{\circ} \mathrm{C}$ storage. ${ }^{6}$

Aim: In this study, we formulated and objectively evaluated sunscreen gels prepared with the use of three different concentrations of mangiferin isolated from $P$. macrocarpa fruits. We tested the gels' physicochemical properties. Additionally, we determined there in vitro SPF using UV spectrophotometry.

Ethics approval: The selection of volunteers and test methods was in accordance with ethical principles specified in the Declaration of Helsinki the study protocol was allowed by the Esa Unggul University Research Ethics committee. For the sensory evaluation and skin irritation test, written informed consent was obtained from all participants before recruitment.

\section{MATERIALS AND METHODS}

\section{Materials}

Mangiferin isolated from P. marcocarpha fruits was naturally obtained from the study by Eff et al. (2018). ${ }^{7}$ Carbophol 934, triethanolamine, propyleneglycol, methylparaben, propylparaben, aquadest and methanol were purchased from a local supplier.

\section{Preformulation}

Table 1 (Jr Allen, 2009) ${ }^{5}$ shows the composition of the gel base used in this study. Accurate quantities of carbophol 934, methylparaben and propylparaben were carefully weighed. Carbophol 934 was dispersed into 50 $\mathrm{mL}$ of distilled water and stirred to naturally form a gel base. Then, methylparaben and propylparaben already dissolved in propyleneglycol were added and the mixture was stirred until it became homogeneous. Mangiferin at three different concentrations of $1.25 \%(\mathrm{~F} 1), 2.5 \%(\mathrm{~F} 2)$ and $5 \%$ (F3) was properly introduced into the gel base and the optimum $\mathrm{pH}$ was accurately adjusted using triethanolamine.

\section{Evaluation of sunscreen gels}

\section{Physicochemical parameters}

The physicochemical parameters examined included color, $\mathrm{pH}$, homogeneity, viscosity, spreadability and stability. To accurately measure viscosity, $8 \mathrm{mg}$ each of F1, F2 and F3 gels was centrifuged at $10-100 \mathrm{rpm}$ at $25^{\circ} \mathrm{C}$ using a Brookfield viscometer (AMETEK Brookfield, Middleboro, MA, USA) with an L4 spindle. To assess spreadability of the gel on the skin, $500 \mathrm{mg}$ each of F1, F2 and F3 gels was placed on transparent glass, which was then covered with another thin glass, loaded with $50 \mathrm{~g}, 100 \mathrm{~g}$ and $150 \mathrm{~g}$, respectively, of weight and left for $60 \mathrm{~s}$. The test was carried out until a constant distribution diameter was obtained ${ }^{11,5}$ Physical stability was tested by storing F1, F2 and F3 gels at three different temperatures: room temperature $\left(25^{\circ} \mathrm{C}\right)$; cold temperature $\left(8^{\circ} \mathrm{C}\right)$; and hot temperature

\section{Table 1: Gel base composition.}

\begin{tabular}{ccc}
\hline Ingredients & Function & Percentage $(w / w)$ \\
\hline Carbophol 934 & Gelling agent & 1 \\
Propylparaben & Preservative & 0.02 \\
Methylparaben & Preservative & 0.18 \\
Propyleneglycol & Humectant & $5 \%$ \\
Triethanolamine & Surfactant/ pH & until pH was neutral (6-7) \\
& adjuster & \\
Aquadest & Solvent & ad 100 ml \\
\hline
\end{tabular}

Source: Modified from Jr Allen (2009). ${ }^{5}$ $\left(40^{\circ} \mathrm{C}\right)$. Possible changes in color, odor and $\mathrm{pH}$ were observed every oneweek period for 8 weeks. ${ }^{5}$

\section{In vitro determination of SPF using UV spectrophotometry}

The UV spectrophotometry method used to measure the SPF was adopted from the study by Petro ${ }^{6}$ and Mansur et al. ${ }^{12}$ Briefly, $100 \mathrm{~mL}$ of methanol was added to $125 \mathrm{mg}$ each of F1, F2 and F3 gels and the mixtures were ultrasonicated for $15 \mathrm{~min}$. Then, $5 \mathrm{~mL}$ of each mixture was diluted with methanol up to $50 \mathrm{~mL}$ to prepare test solutions. The absorption spectra of the test solutions in a $1 \mathrm{~cm}$ cuvette were obtained using an ultraviolet-visible (UV-Vis) spectrophotometer at a wavelength of 290-360 nm. The absorption of the test solutions was measured at intervals of $5 \mathrm{~nm}$ and the minimal absorbance equaled 0.05 .

$\log \mathrm{SPF}=\left[\mathrm{AUC} /\left(\chi_{\mathrm{n}}-\chi_{1}\right)\right] \times 2,{ }^{6}$

where AUC is the total value of absorbance at $\chi_{n}$ and $\chi_{n}-1, \chi_{\text {nis }}$ the wavelength that provided an absorbance of 0.05 and $\chi 1$ is a wavelength of $290 \mathrm{~nm}$.

\section{Sensory evaluation (hedonic test)}

A questionnaire was presented to 30 untrained panelists, who provided their opinions on the color, aroma and comfort of F1, F2 and F3 gels. Criteria for inclusion of potential panelists are as follows, a minimum age of 18 years or more; healthy especially during the carrying out of sensory testing and no history of allergies or sensitivity to the product being tested. The responses were assessed using a 9-point hedonic scale, with 1 as the lowest and 9 as the highest score: 1, dislike extremely; 2, dislike very much; 3 , dislike moderately; 4 , dislike slightly; 5 , neither like nor dislike; 6 , like slightly; 7 , like moderately; 8 , like very much; and 9 , like extremely. Data were analyzed using the Friedman test. ${ }^{13,14}$

\section{Skin irritation}

For the skin irritation test, we selected 20 female volunteers who met the following inclusion criteria: female, age $\geq 18$ years old, physically and mentally healthy, skin free from lesions; and no history of allergy. All volunteers provided informed consent. For the patch test, $\sim 0.5 \mathrm{~g}$ each of gels F1, F2 and F3 was applied to a $\sim 6 \mathrm{~cm}^{2}$ area on the outer upper arm of the 20 volunteers and the area was covered with gauze for up to $4 \mathrm{hr}$ (the exposure time was increased progressively from 15 and $30 \mathrm{~min}$ to $1,2,3$ and $4 \mathrm{hr}$ ). Irritation reactions were recorded at 24,48 and $72 \mathrm{hr}$ after removal of patches. ${ }^{15,16}$ The degree of irritation was assessed using a 4-point scale, depending on the severity of erythema and edema:

- $\quad$ Erythema

- $\quad 0$, no erythema;

- 1 , little erythema (diameter $<25 \mathrm{~mm}$ );

- $\quad 2$, erythema clearly visible (diameter $25.1-30 \mathrm{~mm}$ );

- $\quad 3$, medium erythema (diameter 30.1-35 mm);

- 4 , severe erythema (diameter $35 \mathrm{~mm}$ ).

- Edema:

- $\quad 0$, no edema:

- $\quad 1$, slight edema (almost invisible);

- $\quad 2$, edema with a clearly defined edge (thickness $<1 \mathrm{~mm}$ );

- $\quad 3$, mild edema (rising edge $\pm 1 \mathrm{~mm}$ );

- 4 , severe edema (thickness $<1 \mathrm{~mm}$ ).

During assessment, the volunteers were allowed to wash the skin with water only (no soap, detergent, or cosmetic product).

The irritation index of each of the F1, F2 and F3 gels was calculated using the following formula: 
(Erythema score at $24+48+72 \mathrm{hr}+$ Edema score at $24+48+72 \mathrm{hr}$ )/Number of volunteers

The severity of irritant reaction was determined by comparing the irritation index with the degree of irritation as follows: 0.0 , no irritation;
$0.1-0.4$, very slight irritation; $0.41-1.9$, slight irritation; $2.0-4.9$, moderate irritation; and 5.0-8.0, severe irritation. ${ }^{16}$

\section{RESULTS}

\section{Physicochemical parameters}

Table 2: Physicochemical parameter evaluation of gels.

\begin{tabular}{|c|c|c|c|c|c|c|c|}
\hline \multirow[t]{2}{*}{ Formulation } & \multirow[t]{2}{*}{ Color } & \multirow[t]{2}{*}{$\mathrm{pH}$} & \multirow[t]{2}{*}{ Homogeneity } & \multirow[t]{2}{*}{ Viscosity (cps) } & \multicolumn{3}{|c|}{$\begin{array}{l}\text { Spreadability } \\
(\mathrm{cm})\end{array}$} \\
\hline & & & & & $50 \mathrm{~g}$ & $100 \mathrm{~g}$ & $150 \mathrm{~g}$ \\
\hline $\mathrm{F} 1$ & Pale yellow & 6.0 & Homogenous & 21890 & 3.5 & 4.05 & 4.45 \\
\hline $\mathrm{F} 2$ & Bright yellow & 5.8 & Homogenous & 23270 & 3.3 & 3.95 & 4.8 \\
\hline F3 & Bright yellow & 5.9 & Homogenous & 29880 & 3.7 & 4.1 & 5.2 \\
\hline
\end{tabular}

F1: 1.25\% mangiferin, F2: 2.5\% mangiferin, F3: 5\% mangiferin

Table 3: Physicochemical parameter evaluation results of $F 1, F 2$ and $F 3$ gels stored at $8^{\circ} \mathrm{C}, 25^{\circ} \mathrm{C}$ and $40^{\circ} \mathrm{C}$, respectively.

\begin{tabular}{|c|c|c|c|c|c|c|c|c|c|c|c|c|c|c|c|c|c|c|c|c|c|c|c|c|c|}
\hline \multirow{3}{*}{$\begin{array}{l}\text { Para } \\
\text { meter }\end{array}$} & \multirow{3}{*}{$\begin{array}{l}\text { Tem } \\
\text { Pera } \\
\text { ture } \\
\left({ }^{\circ} \mathrm{C}\right)\end{array}$} & \multicolumn{24}{|c|}{ Week } \\
\hline & & \multicolumn{3}{|c|}{1} & \multicolumn{3}{|c|}{2} & \multicolumn{3}{|c|}{3} & \multicolumn{3}{|c|}{4} & \multicolumn{3}{|c|}{5} & \multicolumn{3}{|c|}{6} & \multicolumn{3}{|c|}{7} & \multicolumn{3}{|c|}{8} \\
\hline & & F1 & $\mathrm{F} 2$ & F3 & $\mathrm{F} 1$ & $\mathrm{~F} 2$ & F3 & F1 & F2 & F3 & $\mathrm{F} 1$ & $\mathrm{~F} 2$ & F3 & $\mathrm{F} 1$ & $\mathrm{~F} 2$ & F3 & F1 & $\mathrm{F} 2$ & F3 & F1 & F2 & F3 & F1 & F2 & F3 \\
\hline \multirow{3}{*}{ Color } & 8 & PY & BY & BY & PY & BY & BY & PY & BY & BY & PY & BY & BY & PY & BY & BY & PY & BY & BY & PY & BY & BY & PY & BY & BY \\
\hline & 25 & PY & BY & BY & PY & BY & BY & PY & BY & BY & PY & BY & BY & PY & BY & BY & PY & BY & BY & PY & BY & BY & PY & BY & BY \\
\hline & 40 & PY & BY & BY & PY & BY & BY & PY & BY & BY & PY & BY & BY & PY & BY & BY & PY & BY & BY & PY & BY & DY & PY & BY & DY \\
\hline \multirow{3}{*}{$\mathrm{pH}$} & 8 & 6.0 & 5.8 & 5.9 & 6.0 & 5.8 & 5.9 & 6.0 & 5.8 & 5.9 & 6.0 & 5.8 & 5.9 & 6.0 & 5.8 & 5.9 & 6.0 & 5.8 & 5.9 & 6.0 & 5.8 & 5.9 & 6.0 & 5.8 & 5.9 \\
\hline & 25 & 6.0 & 5.8 & 5.9 & 6.0 & 5.8 & 5.9 & 6.0 & 5.8 & 5.9 & 6.0 & 5.8 & 5.9 & 6.0 & 5.8 & 5.9 & 6.0 & 5.8 & 5.9 & 6.0 & 5.8 & 5.9 & 6.0 & 5.8 & 5.9 \\
\hline & 40 & 6.0 & 5.8 & 5.9 & 6.0 & 5.8 & 5.9 & 6.0 & 5.8 & 5.9 & 6.0 & 5.8 & 5.9 & 6.0 & 58 & 5.9 & 6.0 & 5.8 & 5.9 & 6.0 & 5.8 & 5.9 & 6.0 & 5.8 & 5.9 \\
\hline \multirow{3}{*}{ Homogeneity } & 8 & $\mathrm{H}$ & $\mathrm{H}$ & $\mathrm{H}$ & $\mathrm{H}$ & $\mathrm{H}$ & $\mathrm{H}$ & $\mathrm{H}$ & $\mathrm{H}$ & $\mathrm{H}$ & $\mathrm{H}$ & $\mathrm{H}$ & $\mathrm{H}$ & $\mathrm{H}$ & $\mathrm{H}$ & $\mathrm{H}$ & $\mathrm{H}$ & $\mathrm{H}$ & $\mathrm{H}$ & $\mathrm{H}$ & $\mathrm{H}$ & $\mathrm{H}$ & $\mathrm{H}$ & $\mathrm{H}$ & $\mathrm{H}$ \\
\hline & 25 & $\mathrm{H}$ & $\mathrm{H}$ & $\mathrm{H}$ & $\mathrm{H}$ & $\mathrm{H}$ & $\mathrm{H}$ & $\mathrm{H}$ & $\mathrm{H}$ & $\mathrm{H}$ & $\mathrm{H}$ & $\mathrm{H}$ & $\mathrm{H}$ & $\mathrm{H}$ & $\mathrm{H}$ & $\mathrm{H}$ & $\mathrm{H}$ & $\mathrm{H}$ & $\mathrm{H}$ & $\mathrm{H}$ & $\mathrm{H}$ & $\mathrm{H}$ & $\mathrm{H}$ & $\mathrm{H}$ & $\mathrm{H}$ \\
\hline & 40 & $\mathrm{H}$ & $\mathrm{H}$ & $\mathrm{H}$ & $\mathrm{H}$ & $\mathrm{H}$ & $\mathrm{H}$ & $\mathrm{H}$ & $\mathrm{H}$ & $\mathrm{H}$ & $\mathrm{H}$ & $\mathrm{H}$ & $\mathrm{H}$ & $\mathrm{H}$ & $\mathrm{H}$ & $\mathrm{H}$ & $\mathrm{H}$ & $\mathrm{H}$ & $\mathrm{H}$ & $\mathrm{H}$ & $\mathrm{H}$ & $\mathrm{H}$ & $\mathrm{H}$ & $\mathrm{H}$ & $\mathrm{H}$ \\
\hline \multirow{3}{*}{$\begin{array}{c}\text { Phase } \\
\text { separation }\end{array}$} & 8 & - & - & - & - & - & - & - & - & - & - & - & - & - & - & - & - & - & - & - & - & - & - & - & - \\
\hline & 25 & - & - & - & - & - & - & - & - & - & - & - & - & - & - & - & - & - & - & - & - & - & - & - & - \\
\hline & 40 & - & - & - & - & - & - & - & - & - & - & - & - & - & - & - & - & - & - & - & - & + & - & - & + \\
\hline
\end{tabular}

PY, pale yellow; BY, bright yellow; DY, dark yellow; H, homogeneity; -, no change; +, slight change

Sun Protection factor

Table 4: Sun Protection Factor (SPF) value of gels.

\begin{tabular}{cc}
\hline Formulation & SPF value \\
\hline F1 & 11.2 \\
F2 & 38.6 \\
F3 & 88.53 \\
\hline
\end{tabular}

\section{Skin irritation}

Safety testing is essential before raw materials or end products can be sold to consumers. The degree of irritation for all 20 volunteers in this study was 0 , indicating that gels F1, F2 and F3 do not irritate the skin.

\section{DISCUSSION}

Development of sunscreen preparations leading to the use of natural materials today is preferred because the public more simply accepts it. People assume natural ingredients are safer to use and less negative im-
Sensory evaluation (hedonic test) Table 5: Sensory evaluation results.

\begin{tabular}{ccccc}
\hline \multirow{2}{*}{$\begin{array}{c}\text { Formula } \\
\text { tion }\end{array}$} & \multicolumn{4}{c}{ Mean rank } \\
\cline { 2 - 5 } & Color & Consistency & Comfort & Aroma \\
\hline F1 & 3.65 & 3.90 & 3.75 & 2.95 \\
F2 & 2.85 & 2.95 & 4.25 & 3.10 \\
F3 & 3.60 & 3.60 & 4.05 & 3.25 \\
\hline
\end{tabular}

pact than chemicals. Potential natural material as sunscreen is Phalleria macrocarpa. P. macrocarpa contains the main compound, which is a benzophenone derivative that possesses a protective effect against the dangers posed by ultraviolet light. ${ }^{7,8}$

Table 2 shows gel product and the physicochemical parameter evaluation results of F1, F2 and F3 gels, respectively. Three gel formula were found to be homogeneous. Freshly prepared F1 gel was pale yellow, while F2 and F3 gels were bright yellow. The pH of the F1, F2 and F3 gels ranged 
from 5.8 to 6.0 , corresponding to the human skin $\mathrm{pH}$ of $4.5-7$. So, if applied to the skin, the three gels would not cause irritation.

Viscosity is a measure of a fluid's resistance to flow: the higher the viscosity, the greater the resistance to flow. Viscosity is an important parameter for evaluating gel preparations. In this study, F1, F2 and F3 gels had a viscosity of 2,000-50,000 cps, meeting the requirements of sunscreen preparations. ${ }^{17,18}$ Spread ability indicates the extent to which a gel spreads when applied to skin and the therapeutic potential of a gel formulation depends on this spread ability. In this study, the gels F1, F2 and F3 had good spread ability in the range of following 3.5-4,4 for F1, 3,3-4,8 for $\mathrm{F} 2$ and $3,7-5,2$ for $\mathrm{F} 3{ }^{8}$

Table 3 shows the physicochemical parameter evaluation results of F1, F2 and F3 gels stored at various temperature for 8 weeks. Physical stability tests determined the physical changes that occurred in gels F1, F2 and F3. Physical stability tests are associated with shelf life in storage of a gel formulation and are essential to ensure the quality, safety and efficacy of the product. These tests play an important role in the development and improvement of formulations, determining validity and monitoring physical and chemical characteristics. ${ }^{19}$ The test parameters evaluated for physical stability were color, $\mathrm{pH}$, homogeneity and phase separation. Organoleptic observations at storage temperatures of $8^{\circ} \mathrm{C}, 25^{\circ} \mathrm{C}$ and $40^{\circ} \mathrm{C}$ for 8 weeks did not show any changes in color, $\mathrm{pH}$, homogeneity and phase separation in F1 and F2 gels. However, we observed a few changes in color and phase separation in gel F3 at weeks 7 and 8: the color changed from pale yellow to dark yellow; and there was slight phase separation presumably due to the oily phase separation promoted at a higher temperature.

The effectiveness of F1, F2 and F3 gels was tested by determining their SPF in vitro using the method developed in the study by Mansur et al. (1986). ${ }^{12}$

F1, F2 and F3 gels showed high absorbance at 290-360 nm wavelength. Table 4 represent Sun Protection Factor (SPF) value of gels. The SPF was 11.2, 38.6 and 88.53, respectively, indicating that all three gels have sunscreen activity. Increasing the mangiferin might increase the SPF because of increasing amounts of phenolic compounds, which have photo protective activity due to the presence of double bonds that are conjugated with a single bond and are involved in the absorption of sunlight. ${ }^{20}$ P. marcocarpha fruits have been traditionally used as medicines, either singly or mixed with other traditional medicines. New compounds discovered in these fruits are benzophenone and xanthine glycosides: mahkoside A; mangiferin; and 6,4-DHMP. In vitro and in vivo tests of these compounds show that they act as sunscreens. Mangiferin is a polyphenol compound contained in leaves (Mangifera indica) and fruits ( $P$. marcocarpha) and has antioxidant properties. At a concentration of $100 \mathrm{ppm}$, mangiferin has a SPF of 2.82 and, at concentrations of $12.5 \%, 25 \%$ and $50 \%$, it decreases erythema severity and erythema diameter significantly compared to negative controls $(p<0.05) .5,21,22$ Some phytoconstituents, such as proanthocyanidin, quercetin, apigenin, silymarin and carotenoid are potential ingredients of sunscreens. Phenolic compounds found in specific plants are potential agents for typically preventing the harmful effects of direct UV radiation on skin. ${ }^{23}$ Evidence suggests that various forms of polyphenols used both orally and topically are beneficial for skin health and prevent sunburn. Polyphenols can be used as a possible alternative for skin care and effective protection against the harmful effects of direct UV radiation, but large-scale clinical studies are still required in order to adequately assess the use of polyphenols in effective prevention of sunburns, both topically and orally. Active polyphenolic compounds, such as flavonoids, have striking similarities with organic UV filters that possess chromophores and aromatic rings having not only photo protective effects but also anti-oxidant activity. ${ }^{24}$ Free radicals produced endogenously during cellular metabolism or exogenously sourced from UV radiation and pollution can damage the skin at levels both cellular and tissue. Although the body contains endogenous antioxidants to prevent free-radical damage, this system has limited capacity and leads to oxidative stress, triggering carcinogenesis. Using topical preparations with antioxidant activity can neutralize exogenous and endogenous oxygen species. ${ }^{1}$

Sensory evaluation / hedonic test results (Table 5) represent F1 gel was the most preferred formulation on the parameters of color and consistency, while F2 and F3 gels were most preferred on the parameters of comfort and aroma, respectively. The hedonic test is the most widely used test to measure the level of preference for a product. ${ }^{13,14}$

Results from skin irritation test showed that mangiferin sunscreen gel works as a surfactant, so it prevents skin irritation. Mangiferin has antiinflammatory and antioxidant activities. It inhibits the expressions of Interleukin 6 (IL-6) and IL-1 $\beta$, decreases total inflammatory cell infiltration and eosinophils and lowers prostaglandin (PG) D2. Mangiferin also inhibits Immunoglobulin E (IgE) production, anaphylaxis, histamineinduced vascular permeability, histamine release and the lymphocyte proliferative response..$^{25}$

\section{CONCLUSION}

Gel formulations containing mangiferin at concentrations of $1.25 \%, 2.5 \%$ and 5\% are potential and active as sunscreens with Sun Protection Factor (SPF) values of $11.2,38.6$ and 88.53 , respectively. All three gel formulas meet the physicochemical parameter and stable at temperatures $8^{\circ}, 25^{\circ}$ and $40^{\circ} \mathrm{C}$ for eight weeks of storage. A gel containing $2.5 \%$ concentration of mangiferin is the most preferred formula. The three gel formulas were tolerated because they did not irritate respondents.

\section{ACKNOWLEDGEMENT}

This research was funded by grant from Indonesia Ministry of Research, Technology and Higher Education (KEMENRISTEK DIKTI), Indonesia.

\section{CONFLICT OF INTEREST}

The authors declare no conflict of interest

\section{ABBREVIATIONS}

SPF:SunProtectionFactor;DHMP:dihydroxi-4-methoxybenzophenone2-O-- $\beta$-D-glucopyranoside.

\section{REFERENCES}

1. Mishra AK, Mishra A, Chattopadhyay P. Herbal cosmeceuticals for photoprotec tion from ultraviolet B radiation: A review. Trop J Pharm Res. 2011;10(3): 351-60.

2. Donglikar MM, Deore SL. Development and Evaluation of Herbal Sunscreen. Pharmacogn J. 2016;9(1):83-97.

3. Kumar D, Rajora G, Parkash O, Antil MH, Kumar V. Herbal cosmetics: An over view. Int J Adv Sci Res. 2016;1(4):36-41.

4. Chen Q. Evaluate the Effectiveness of the Natural Cosmetic Product Compared to Chemical-Based Products. Int J Chem. 2009;1(2):57-9.

5. Jr Allen LV. The Art, Science and and Technology of Pharmaceutical Compounding. J Pharm Technol. 2009;25:271-84

6. Petro AJ. Correlation of spectrophotometric data with sunscreen protection factors. Int J Cosmet Sci. 1981;3(4):185-96.

7. Eff ARY, Pertiwi RD, Rakhmawati I, Utami TP. In-vitro and in-vivo sunscreen activity of Active compounds isolated from Fruits of Phaleria marcocarpha (Scheff.) Boerl J Young Pharm. 2018;10(2):S483-7.

8. Kawakami CM, Gaspar LR. Biology Mangiferin and naringenin affect the photostability and phototoxicity of sunscreens containing avobenzone. J Photochem Photobiol Biol. 2015;151:239-47.

9. Kim HS, Song JH, Youn UJ, Hyun JW, Jeong WS, Lee MY, et al. Inhibition of UVB-induced wrinkle formation and MMP-9 expression by mangiferin isolated from Anemarrhena asphodeloides. Eur J Pharmacol. 2012;689(1-3):38-44.

10. Kaur LP, Guleri TK. Topical Gel: A Recent Approach for Novel Drug Delivery. Asian J Biomed Pharm Sci. 2013;3(17):1-5 
11. Sayuti NA. Formulation and physical stability test gel formulation from leaves of Ketepeng Cina (Cassia alata L.). J Kefarmasian Indones. 2015;5(2):74-82.

12. Mansur JS, Breder MN, Mansur MCA, Azulay RD. Determination of protecting factor by spectrophotometry. An Bras Dermatol. 1986;61:121-4.

13. Ángeles TDL, Tayupanta M, Espadero M, Mancheno M, Peña S. Sensory analysis of cosmetic formulations made with essential oils of Aristeguietia g/utinosa (Matico) and Ocotea quixos (Ishpingo ). Int J Phytocosmetics Nat Ingredients. 2018;5(5):1-5.

14. Kim H, House LA, Odabasi AZ, Sims CA. Sensory and Hedonic Evaluation in Response to Food-Cue Exposure: The Case of Juicing Demonstration of Fresh Oranges. Int J Mark Stud. 2015;7(5):65-75.

15. Jirova D, Liebsch M, Basketter D, Spiller E, Kejlova K, Bendova H, et al. Comparison of human skin irritation and photo-irritation patch test data with cellular in vitro assays and animal in vivo data. Proc $6^{\text {th }}$ World Congress on Alternatives and Animal Use in the Life Sciences. 2007;14:359-65.

16. Wang J, Li Z, Sun F, Tang S, Lv P. Evaluation of dermal irritation and skin sensitization due to vitacoxib. Toxicol Reports. 2017;4:287-90.

17. Smaoui S, Ben H, Ben C, Kadri A. Development and stability studies of sunscreen cream formulations containing three photo-protective filters. Arab $J$ Chem. 2017;10(Suppl 1):S1216-22.

18. Sopyan I, Gozali D, Tiassetiana S. Formulation of tomato extracts (Solanum lycopersicum L.) as a sunscreen lotion. Natl J Physiol Pharm Pharmacol. 2018;8(3):453-8.

19. Bajaj S, Singla D, Sakhuja N. Stability Testing of Pharmaceutical Products. J Appl Pharm Sci. 2012;2(3):129-38.

20. Polonini HC, Brandãoa MAF, Raposoa NRB. A natural broad-spectrum sunscreen formulated from the dried extract of Brazilian Lippia sericae as a single UV filter. R Soc Chem. 2016;0(1-3):1-9.

21. Yanti AR, Radji M, Munim A, Suyatna FD. Methanol Extract of [Phaleria macrocarpa (Scheff.)] Boerl improved renal and liver histological changes in fructose $10 \%$ induced rats. J Pharmaceuical Biol Res. 2014;2(1):79-84.

22. Yanti AR, Radji M, Munim A, Suyatna FD. Effects of the Methanol extracts [Phaleria macrocarpa (Scheff. )] Boerl fruits on Angiotensin Converting Enzyme (ACE activity. Int J Adv Pharmacy Biol Chem. 2014;3(4):912-8.

23. Anitha T. Medicinal Plants Used in Skin Protection. Asian J Pharm Clin Res. 2012;5(3):3-6.

24. Rasheed A, Shama SN, Mohanalakshmi S, Ravichandran V. Formulation, characterization and in vitro evaluation of herbal sunscreen lotion. Orient Pharm Exp Med. 2012;12(4):241-6.

25. Imran M, Ashrad MS, Butt MS, Kwon JH, Arshad MU, Sultan MT. Mangiferin: A natural miracle bioactive compound against lifestyle related disorders. Lipids Health Dis. 2017;16(84):1-7.

Cite this article: Eff ARY, Rahayu ST, Saraswati H, Mun'im A. Formulation and Evaluation of Sunscreen Gels Containing Mangiferin Isolated from Phaleria macrocarpa Fruits. Int. J. Pharm. Investigation. 2019;9(3):141-5. 